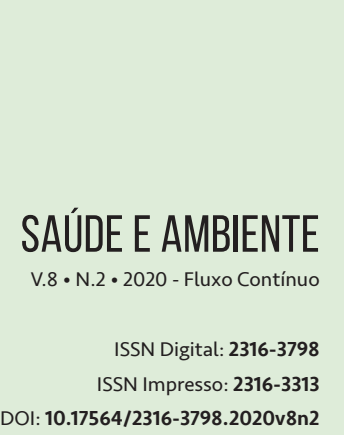

DOI: $10.17564 / 2316-3798.2020 v 8 n 2$
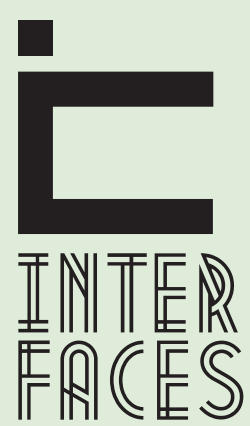

CIENTÍFICAS

\title{
ANÁLISE DAS CAUSAS DA DESATIVAÇÃO DO SISTEMA CURURUCA DE CAPTAÇ̃̃O SUPERFICIAL EM PAÇO DO LUMIAR, MARANHÃO
}

\section{ANALYSIS OF THE CAUSES OF THE DEACTIVATION OF THE CURURUCA SYSTEM OF SURFACE WATER CAPTURE IN PAÇO DO LUMIAR, MARANHÃO}

\section{ANÁLISIS DE LAS CAUSAS DE LA DESACTIVACIÓN DEL SISTEMA CURURUCA DE CAPTACIÓN SUPERFICIAL EN PAÇO DO LUMIAR, MARANHÃO}

\section{RESUMO}

A problemática relacionada ao abastecimento de água tem sido amplamente destacada no cenário mundial. Essas dificuldades podem ocorrer devido a inúmeros motivos, por exemplo, os resultados do processo intenso e desorganizado de urbanização e industrialização, de gestões ineficientes e mau planejamento dos recursos hídricos e da infraestrutura inadequada do sistema de abastecimento de água. Diante disso, o presente trabalho indagou por meio de pesquisas realizar um levantamento das possíveis causas que resultaram na desativação do sistema de captação de água do Rio Cururuca, o qual pertence à bacia Santo Antônio, localizado na Ilha do Maranhão nos municípios de São José de Ribamar e Paço do Lumiar. Por meio desse sistema de captação de água que na época contribuía com $312 \mathrm{~m}^{3} \cdot \mathrm{h}^{-1}$ de água para abastecer o conjunto Maiobão, o mesmo continha 4.666 residências e com uma população acima dos 20.000 habitantes, esse sistema foi interrompido em consequência de sua quantidade e qualidade do recurso hídrico que deixou de serem suficientes para atender às demandas da população que habita a região citada. Através do auxílio do geoprocessamento, foi possível observar através da análise de dados de uma escala temporal que o uso e ocupação do solo de forma desordenada teve uma grande contribuição para o problema abordado.

\section{PALAVRAS-CHAVE}

Pollyanna Pedrosa Gonçalves ${ }^{3}$ Larissa Kelly Nogueira Vieira ${ }^{4}$ Manoel Cariolano da Silva Neto ${ }^{5}$ Thalissa Cantanhede Lindoso ${ }^{6}$ Camila Everton Guterres ${ }^{7}$ Nathalia Cunha Almeida Pinheiro ${ }^{8}$
Abastecimento de água, Sistema desativado, Paço do Lumiar, Maranhão. 


\section{ABSTRACT}

Problems related to water supply have been widely highlighted on the world stage. These difficulties may occur due to several reasons, for example, the results of the intense and disorganized processes of urbanization and industrialization, inefficient management and poor planning of water resources and inadequate infrastructure of the water supply system. Therefore, the present study investigated the possible causes that resulted in the deactivation of the water capture system of the Cururuca River, which belongs to the Santo Antônio river basin, located on the Island of Maranhão in the municipalities of São José de Ribamar and Paço do Lumiar, through this system of water abstraction at that time contributed $312 \mathrm{~m}^{3}$.h-1 of water to supply the whole Maiobão neighborhood, it contained 4,666 households and a population number over 20,000 inhabitants, this system was interrupted as a result of its quantity and quality of the water resource that was no longer sufficient to meet the demands of the population that inhabits the region. Through the aid of geoprocessing techniques, it was possible to observe through the data analysis of a temporal scale the disorderly use and occupation of the soil contributed to the problem addressed.

\section{KEYWORDS}

Water supply, System Off, Paço do Lumiar, Maranhão.

\section{RESUMEN}

Los problemas relacionados con el suministro de agua se han destacado ampliamente en el escenario mundial. Estas dificultades pueden ocurrir debido a varias razones, por ejemplo, los resultados de los procesos intensos y desorganizados de urbanización e industrialización, gestión ineficiente y planificación deficiente de los recursos hídricos e infraestructura inadecuada del sistema de suministro de agua. Por lo tanto, el presente estudio investigó las posibles causas que resultaron en la desactivación del sistema de captura de agua del río Cururuca, que pertenece a la cuenca del río Santo Antônio, ubicada en la isla de Maranhão, en los municipios de São José de Ribamar y Paço do Lumiar, a través de este sistema de extracción de agua que en ese momento aportaba $312 \mathrm{~m}^{3}$.h-1 de agua para abastecer a todo Maiobão, contenía 4,666 hogares y una población de más de 20,000 habitantes, este sistema se interrumpió debido a su cantidad y la calidad del recurso hídrico que ya no era suficiente para satisfacer las demandas de la población que habita la región. Mediante la ayuda de técnicas de geoprocesamiento, fue posible observar mediante el análisis de datos de una escala temporal que el uso y la ocupación del suelo de una manera desordenada tuvo una gran contribución al problema abordado. 


\section{PALABRAS CLAVE}

Suministro de agua, Sistema apagado, Paço do Lumiar, Maranhão.

\section{INTRODUÇ̧̃̃O}

A água é essencial para a vida, tendo em vista os diversos fins para os quais ela é empregada. Também é um elemento essencial ao corpo humano e utilizada como matéria-prima de diversos processos industriais. $E$ as funções da água não param por aí: ela também é utilizada para geração de energia, como parte do ciclo de produção vegetal e ainda é o meio utilizado pelos transportes fluviais (OLIVEIRA, 2016). No amplo contexto social do século XXI, a intensa urbanização e o aumento da demanda pela água associada a problemas na gestão geram problemas hídricos e ocasionam uma exaustão desses recursos (DERISIO, 2012).

A Agência Nacional de Águas (ANA) destaca que são necessárias ações conjuntas de vários setores da sociedade aliada a recursos financeiros significativos para manter ou restabelecer a qualidade e a quantidade de água dos recursos hídricos do Brasil, destacando desafios como melhoria das condições de saneamento, efetivação integrada dos planos de saneamento, de recursos hídricos e diretores municipais, disciplinamento do uso e ocupação do solo, práticas sustentáveis em áreas agrícolas e industriais etc.

Além de todos estes fatores, a ANA destaca que as mudanças climáticas podem ter repercussões sobre a qualidade e quantidade de água disponível para o ser humano, e, portanto, os corpos hídricos devem ser sempre monitorados (ANA, 2012).

Fundamentais para a manutenção de todos os ciclos naturais, para a manutenção da biodiversidade e da própria vida, os recursos hídricos superficiais tornam-se as principais fontes de abastecimento de água potável do planeta, representados por apenas 0,14\% de toda a água existente na Terra. São essas as águas que participam do movimento e troca com outras áreas e reservatórios superficiais, participando ativamente do processo de abastecimento de água para a população (DERISIO, 2012).

O Brasil possui $12 \%$ da disponibilidade de água doce superficial do mundo, porém cabe destacar que muitos fatores, tanto naturais quanto antrópicos, têm contribuído significativamente para mudanças nos aspectos quantitativos e qualitativos dos corpos hídricos do país (ANA, 2012). Em virtude disso, a Política Nacional de Recursos Hídricos instituída pela Lei Federal n 9.433, de 8 de janeiro de 1997, estabelece como objetivo assegurar à atual e às futuras gerações a disponibilidade de água em padrões de qualidade adequados aos seus diversos usos (BRASIL, 1997).

Dentro desse contexto, o Estado do Maranhão se destaca por possuir um grande potencial de recursos hídricos superficiais. A ilha de São Luís, por exemplo, composta pelos municípios de São Luís, São José de Ribamar, Paço do Lumiar e Raposa, possui rios importantes, com destaque para os rios Anil, Bacanga, Tibiri, Paciência, Maracanã, Calhau, Pimenta, Cururuca, Jaguarema, entre outros. Os Rios Anil, Jaguarema, Paciência e Cururuca, por exemplo, já foram responsáveis pelo abastecimento 
de água de parte da população da ilha, porém esses sistemas de abastecimento foram desativados. Macêdo (2005) já destacava que os rios da ilha de São Luís têm passado por um processo de degradação intenso, o que tem ocasionado até a extinção de alguns de seus corpos hídricos.

Esse processo crescente de degradação dos rios e os impactos que eles vêm sofrendo na ilha podem ser contribuintes significantes para a desativação de sistemas de captação de água para abastecimento de água para consumo humano.

Destacam-se neste contexto a desativação do Sistema Cururuca que captava e tratava a água do Rio Cururuca e abastecia vários bairros, destacando-se o conjunto Maiobão (Paço do Lumiar-MA). Nessa perspectiva, este trabalho teve como objetivo principal a análise das causas da desativação do Sistema Cururuca de captação de água superficial para consumo humano localizado no município de Paço do Lumiar, Maranhão.

\section{METODOLOGIA}

O Sistema do Cururuca está desativado atualmente e localiza-se no município de Paço do Lumiar, na comunidade Cururuca, com a captação de água realizada no Rio Cururuca, inserido na bacia do Rio Santo Antônio (FIGURA 1), sendo que esta faz parte dos municípios de São José de Ribamar e de Paço do Lumiar (ALMEIDA, et al., 2011). Situado ao leste da ilha do Maranhão, recebe fluxos diretos das correntes de ar oriundo do Oceano Atlântico. Com limitação ao norte com o município da Raposa, e leste, oeste e sul com o município de São José de Ribamar. Esse Sistema está enquadrada pelas coordenadas geográficas latitude $2^{\circ} 32^{`} 23,58^{\prime \prime}$ S e de longitude $44^{\circ} 06^{`} 31,45^{\prime \prime} 0$.

Figura 1 - Localização da Micro Bacia do Rio Santo Antônio

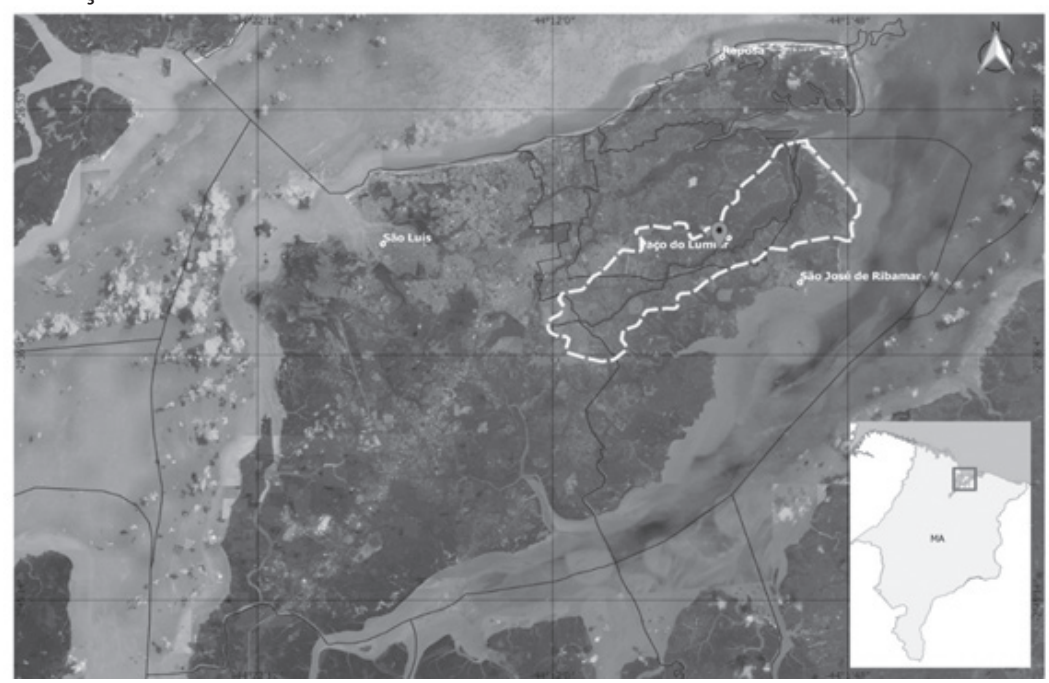

Fonte: NUGEO (2013). 
O clima da área de estudo corresponde ao tipo Aw, tropical úmido, caracterizado por dois períodos bem definido: um chuvoso, com altos excedentes pluviométricos, que se estende de janeiro a julho e outro seco, apresentando deficiência hídrica, que compreende o período de agosto a dezembro, com totais anuais de precipitações em torno de $2.000 \mathrm{~mm}$, com temperaturas altas variando entre 26 e $35^{\circ} \mathrm{C}$. (MARFRA, 2004).

Em relação à vegetação na área objeto de estudo, encontram-se três conjuntos florísticos, representados pela floresta secundária mista e capoeira, nas áreas emersas (tabuleiros) e os mangues na planície fluviomarinha do Rio Cururuca. Essa vegetação original tem sido bastante modificada em virtude da intensa ocupação da área.

De acordo com Araújo, Teles e Lago (2009), a bacia do rio Santo Antônio possui uma área de $100,46 \mathrm{~km}^{2}$ e uma hierarquia fluvial de $4^{\mathrm{a}}$ ordem. 0 comprimento da rede de drenagem que representa o somatório das medidas de todos os trechos de rios da bacia é de 136,82 Km e o seu perímetro é de 60,04 Km.

O Rio Santo Antônio que dá o nome à bacia, também é denominado de Rio Cururuca, Rio Antônio Esteves, Rio da Mata, Rio Ubatuba, Rio São João, Rio Pindai como descrito por Almeida e colaboradores (2011). Este rio tem seu curso direcionado ao nordeste da Ilha do Maranhão, sendo que na localidade Timbuba segue em sentido Norte por mais 4,5 Km até o encontro com a água salgada. A foz do Rio Santo Antônio possui cerca de 1 Km de largura, desaguando na baía de São José.

\subsection{PROCEDIMENTOS METODOLÓGICOS}

Foram realizadas pesquisas bibliográficas e documentais por meio da consulta de trabalhos acadêmicos, trabalhos técnicos disponíveis em órgãos públicos locais e à legislação pertinente, objetivando levantamento do referencial bibliográfico para a busca de informações sobre os mananciais da Ilha de São Luís-MA que já possuíram sistemas de captação de água para abastecimento humano. Esta etapa permitiu o levantamento de caraterísticas ambientais dos corpos hídricos da ilha, inclusive do rio Cururuca (objeto de estudo), levando-se em consideração a bacia na qual pertence.

Os dados secundários utilizados nesta pesquisa foram obtidos a partir da companhia de saneamento estadual, pois se trata da empresa que tinha a concessão para captar água bruta do Rio Cururuca. Junto a essa companhia foram levantadas informações sobre a identificação dos sistemas de captação de água já desativados na ilha, sobre as características de cada um destes sistemas e sobre os critérios utilizados para desativação deles.

O sensoriamento remoto e o processamento digital de imagens foram fundamentais para realizar todo o planejamento no processo de uso e ocupação do solo. Para tanto, foi feito o levantamento de imagens de satélite no catálogo de imagens do Instituto Nacional de Pesquisas Espaciais (INPE) e o tratamento das imagens foi realizado por meio do programa (Software free) Spring 5.2.3 (CAMARA et al., 2013) disponível gratuitamente na plataforma do INPE.

Além disso, foram levantados dados em campo com intuito de verificar os aspectos ambientais que mais impactam as sub-bacias da qual faz parte o Rio Cururuca. 


\section{RESULTADOS}

O Sistema Cururuca, localizado no município de Paço do Lumiar, tinha sua captação de água no Rio Cururuca, principal curso de água da bacia do Santo Antônio (FIGURA 2). A captação de água bruta era feita por duas bombas, sendo que a adutora transportava essa água para a estação de tratamento de água do tipo compacta com filtração direta de fluxo ascendente, denominada de Filtros Russos, localizada cerca de 125 metros de distância do Rio Cururuca (ALMEIDA et al., 2011).

Figura 2 - Localização do Sistema de capacitação de água do Rio Cururuca

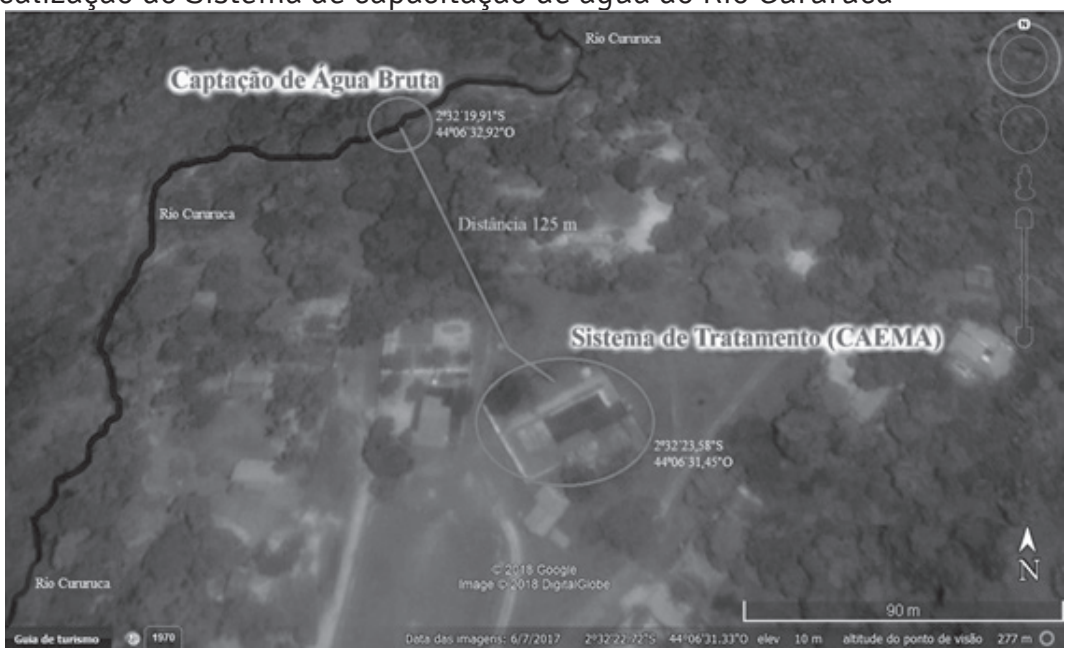

Fonte: INPE (2013).

O sistema de captação era composto por seis filtros de tratamento e quatro bombas, das quais duas funcionavam e as outras eram reservas, uma para água tratada e a outra para água bruta das quais recalcavam a água para uma estação compacta de tratamento de água do tipo filtração direta com fluxo ascendente. Após o tratamento, a água era bombeada para vários bairros, destacando-se nesse contexto o conjunto Maiobão em função de ser bastante povoado, pois era o maior conjunto habitacional do município de Paço do Lumiar no período de operação do Sistema Cururuca, com 4.666 casas.

Richter e Azevedo Netto (1991) afirmam que, também conhecidos como filtros russos ou clarificadores de contato, os filtros de regime ascendente, têm função de clarificar águas de baixa turbidez e matéria mineral. Essa variação de filtro fora originalmente utilizada como unidade completa de clarificação, isto é, recebendo água bruta coagulada, sem passar por floculadores ou decantadores.

0 efluente obtido é diretamente enviado para a desinfecção e reservação/distribuição. Enquanto a água coagulada atravessa a camada filtrante, as impurezas passam a ser em parte retidas e em parte deslocadas na forma de flocos, de uma subcamada para a subsequente, o que acarreta em uma retenção e uma nova locomoção parcial. 
Segundo dados da companhia de saneamento do Estado do Maranhão, no ano de 2003, o sistema produtor do Cururuca tinha uma vazão total de $699,69 \mathrm{~m}^{3} / \mathrm{h}$ e uma produção de volume mensal de $377,946 \mathrm{~m}^{3}$. Só o bairro do Maiobão recebia neste período uma vazão de $312 \mathrm{~m} / \mathrm{h}$ do Sistema Curuca para abastecer o conjunto com água potável, sendo complementada a demanda por poços isolados localizados no próprio bairro que contribuíam com vazão de $537 \mathrm{~m}^{3} / \mathrm{h}$ (SILVA, 2005). Com a desativação do Sistema Cururuca foram perfurados mais poços no Maiobão e nos bairros adjacentes, sendo que o conjunto passou a ser abastecido apenas por uma bateria de poços tubulares profundos.

\subsection{USO E OCUPAÇÃO DO SOLO}

O Rio Cururuca, por drenar áreas de menor densidade demográfica, onde as atividades antrópicas ainda se caracterizam por sua prática rural, tinham suas margens relativamente conservadas, embora a qualidade da água esteja parcialmente comprometida pelos índices de coliformes fecais, além do assoreamento por erosão pluvial (FEITOSA, 1996).

No entanto, a área de estudo encontra-se em grande parte urbanizada com evidências de mata ciliar no decorrer do canal principal do Rio Cururuca. Porém, em alguns trechos ou canais secundários que deveriam estar protegidos pela vegetação natural, encontram-se totalmente ocupados por residências e estabelecimentos comerciais.

O problema inicia-se quando as atividades humanas começam a interferir nos processos do ciclo hidrológico (POLETO, 2014). 0 método aplicado de urbanização descontrolado, geralmente ocorre com a remoção da cobertura vegetal de um ambiente natural e inseridos pavimentação e/ou edificações. A impermeabilização e compactação do solo ocasionam a diminuição da infiltração da água e o aumento do escoamento superficial, consequentemente, provocam maior erosão do solo e aumento do processo de assoreamento, também geram mudanças no nível do lençol freático, podendo ocorrer redução ou esgotamento deste.

Outros problemas são o aumento da ocorrência de enchentes e a poluição das águas superficiais e subterrâneas (ROSA, 2017). As alterações produzidas na superfície da bacia, como a ocupação urbana, atividades de agropecuária e desmatamentos, provocam mudanças nos processos do ciclo, que resultam em modificações na sua disponibilidade, tanto em termos de quantidade como de qualidade (CAPAZ, 2014).

De acordo com Ferreira (2003), na área do alto curso da bacia do rio Santo Antônio, as atividades antrópicas foram intensificadas ao longo das duas últimas décadas, contribuindo em grandes consequências ambientais, principalmente pelas obras de engenharia que se intensificou nas localidades próximas à bacia. As obras de engenharia causam, em geral, alterações em variáveis como infiltração, evaporação e escoamento superficial (POLETO, 2014).

Devido ao lançamento de efluentes domésticos e ao desmatamento da mata ciliar do rio principal, ele vem passando por vários problemas ambientais, resultando na contaminação e poluição das águas, assoreamento, comprometendo quantidade e qualidade da água.

O comprometimento da qualidade da água foi um dos fatores que levou a desativação do Sistema Cururuca no ano de 2006, pois os filtros russos utilizados para o tratamento de água não conseguem tratar com eficiência águas com grande turbidez, pois saturam rapidamente, perdendo a capacidade de produção e vazão em função da grande perda de carga no sistema (RICHTER; AZEVEDO NETTO, 1991). 
No Brasil, para ser considerada potável, a água destinada ao abastecimento do consumo humano deve atender às características de qualidade que estejam de acordo com os valores permissíveis dos parâmetros químicos, físicos, organolépticas e microbiológicos. Estes parâmetros estão regulamentados pela Portaria de Consolidação n 5, de 28 de setembro de 2017, do Ministério da Saúde, em seu anexo XX, que trata do controle e da vigilância da qualidade da água para consumo humano e seu padrão de potabilidade (BRASIL, 2017).

É obrigatória a aplicação desta legislação para as empresas de saneamento, que devem realizar análises periódicas da qualidade da água ofertada nos mais diversos pontos dos sistemas de captação, tais como: tratamento, armazenamento e distribuição de água.

Quaisquer alterações na bacia hidrográfica podem promover variações significativas na qualidade de suas águas, esses problemas são significativos quando as retiradas de água são maiores que a disponibilidade hídrica. Neste âmbito, as bacias próximas a grandes centros urbanos sofrem maiores impactos, agravando diretamente da qualidade das águas devido à urbanização descontrolada, que ocasiona o aumento nos custos de tratamento e restringe os usos da água (ANA, 2013).

Numa visão geral, percebeu-se que o uso e a ocupação do solo na Bacia Santo Antônio (FIGURA 3) estavam num crescente tanto na agropecuária como na expansão da infraestrutura urbana, essa por sua vez já vinha acarretando diversos problemas em toda a extensão da bacia.

Figura 3 - Uso e Ocupação do Solo Bacia Santo Antônio

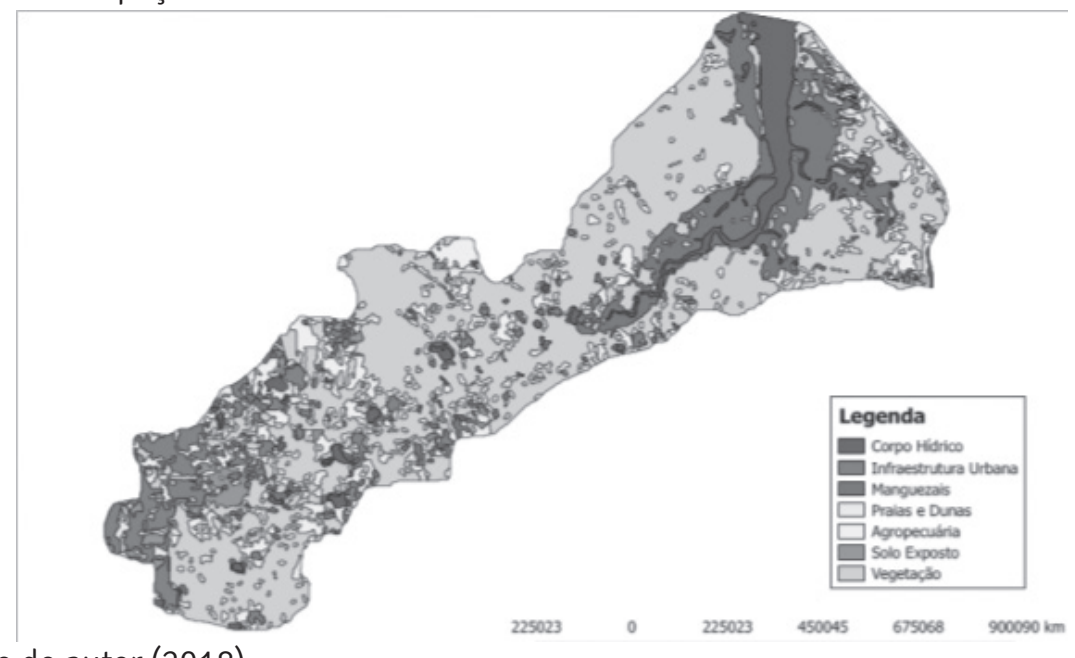

Fonte: Acervo do autor (2018).

É importante ressaltar que nas bacias com a cobertura vegetal natural, a proteção de erosão, a sedimentação e lixiviação excessiva de nutrientes, promove um abastecimento de boa qualidade. De acordo Rocha (1991), as florestas são essenciais para o controle de erosão e de enchentes, uma vez que são fundamentais na recarga do lençol freático, quando situadas em locais adequados. 
Como a bacia hidrográfica compreende uma unidade territorial que drena suas águas para um determinado corpo hídrico, Mota (1999) diz que todas as atividades e usos desenvolvidos nela irão afetar a quantidade e a qualidade de um manancial.

No Maranhão, o crescimento demográfico e mudanças nos padrões de vida da população seguiram o padrão nacional de aumento da demanda do consumo de água. Isto se torna mais evidente quando se analisa o processo de expansão da urbanização ocorrido nos municípios que fazem parte da Região Metropolitana da Grande São Luís (RMGSL) localizados na Ilha (São Luís, São José de Ribamar, Paço do Lumiar e Raposa) nos últimos anos.

A população dos municípios que fazem parte da Ilha de São Luís (FIGURA 4) teve um aumento significativo de acordo com os dados no intervalo de quase 20 anos do Censo Oficial referente aos anos de 1991, 2000 e 2010 do Instituto Brasileiro de Geografia e Estatística (IBGE CIDADES, 2010).

Figura 4 - Comparativo de habitantes dos municípios que fazem parte da Região Metropolitana da Grande São Luís localizados na Ilha, referente aos anos de 1991, 2000 e 2010

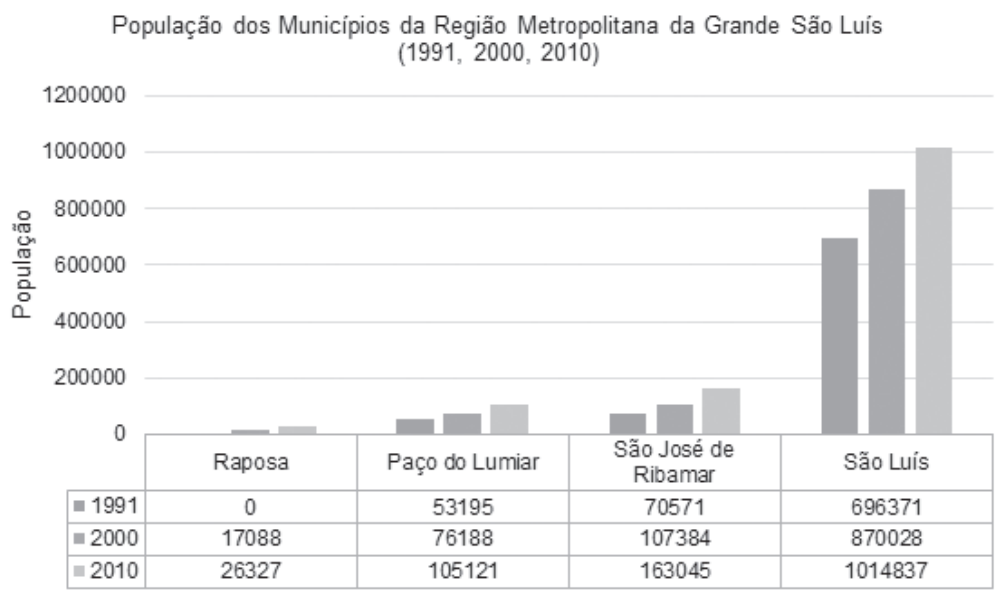

Fonte: IBGE Cidades (2010).

Na perspectiva de entender a dinâmica de uso e ocupação do solo no entorno da bacia Santo Antônio foi realizada uma comparação entre os dados mapeados entres os anos 1992 a 2010 (FIGURA 5). Verificou-se um crescimento no processo de expansão da urbanização ocorrido nos municípios que fazem parte da Região Metropolitana da Grande São Luís (RMGSL), com ajuda das imagens de satélites.

Nesse comparativo, percebeu-se que o uso e ocupação do solo definida no estudo da bacia hidrográfica em questão estão diretamente relacionados aos processos de compactação do solo, queimadas, agropecuária e lançamento de esgoto. Outra observação, é que na área da nascente do curso d'água deveria ser a área mais preservada da bacia, porém, há uma grande área urbanizada e de solo exposto, devido ao desmatamento e a ocupação humana em vários locais no perímetro da bacia. 
Figura 5 - Comparativo da evolução Urbana na Ilha do Maranhão entre 1992 e 2010

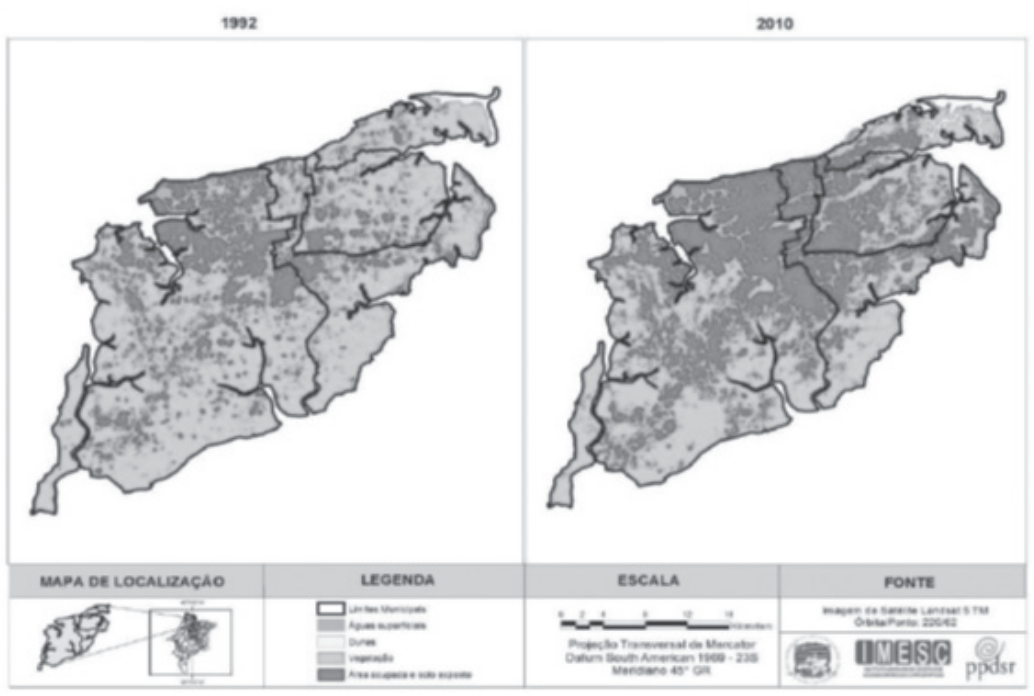

Fonte: IMESC (2011).

\section{DISCUSSÃO}

Com base dos dados do crescimento populacional, de dados obtidos a partir da geração de imagens de satélites no decorrer dos anos 1990 a 2010 e nas observações de campo, percebeu-se que o fator que mais contribuiu para a desativação do sistema de captação de água do Rio Cururuca foi o uso e ocupação do solo de uma maneira desenfreada. Isso foi mais intenso, principalmente, no alto curso do rio, em torno da bacia em estudo, alterando significativamente suas características físicas, químicas e biológicas, modificando a qualidade e quantidade da água.

É importante salientar que os diversos processos que controlam a qualidade da água de um corpo d'água estão relacionados ao complexo equilíbrio. 0 rápido crescimento populacional pelo qual vem passando os municípios da Ilha mencionada acarreta o aumento da ocupação desordenada responsável pelo surgimento de variados problemas de ordem ambiental, estético, socioeconômico ou urbano (SANTOS, 2006).

Apesar do aumento populacional e das mudanças no modo de vida da população residente nos municípios que fazem parte da RMGSL localizados na ilha, verifica-se que as obras de saneamento não acompanharam as atuais demandas, pois é evidente nos noticiários diários da imprensa local as reclamações em virtude da falta de água.

Mesmo com fatores contribuintes para o aumento da demanda de água nos municípios da ilha de São Luís, há uma contradição a partir do momento que foram desativados vários sistemas de captação de água superficial, tais como sistemas Maracanã, Zé Cearense, Olho d’Água e o Sistema Cururuca. 
Por isso é importante fazer uma análise do uso e ocupação do solo em áreas que compreende as bacias hidrográficas, pois grandes rios dos municípios que fazem parte da RMGSL atualmente estão sendo utilizados principalmente com a finalidade de serem diluidores e transportadores de efluentes domésticos e industriais. Contudo é fundamental fazer uma avaliação ambiental, pois as características do meio físico são resultantes principalmente das diferentes formas de uso e ocupação da área e das interferências antrópicas nos processos ambientais (ROMÃO; SOUZA, 2011).

Segundo Nardini (2009), o levantamento do uso do solo, em uma determinada região, torna-se um aspecto de interesse fundamental para a compreensão dos padrões de organização do espaço, onde a compreensão das alterações do meio ambiente, ocasionadas da ação antrópica, proporciona uma visão ampla dos problemas existentes e produz subsídios para gestão dos recursos naturais.

\section{CONSIDERAÇÕES FINAIS}

A perda de sistemas de captação de água para o consumo humano é um indicador de que os corpos hídricos da Ilha de São Luís têm sofrido variações adversas na sua quantidade e/ou da qualidade da água. Portanto, identificou-se os fatores determinantes que levaram à desativação do sistema Cururuca e foram analisadas as suas respectivas causas, destacando-se neste contexto o uso e ocupação do solo de maneira desordenada, onde ele teve sua maior contribuição em vários impactos ao meio ambiente ao longo de toda bacia do Santo Antônio.

É fundamental, para compreensão da dinâmica de ocupação do solo para o estabelecimento de ações de planejamento para a bacia hidrográfica, incrementando ainda a importância dos dados obtidos por meio de imagens de satélites.

É importante salientar que estes resultados poderão servir como base para posteriormente serem repensadas as estratégias adotadas pelo poder público para evitar que essa problemática não se repita em outros corpos hídricos superficiais da ilha utilizados atualmente para captação de água para consumo humano.

\section{REFERÊNCIAS}

ALMEIDA, N.C. et al. Impacto ambiental na bacia hidrográfica do Rio Santo Antônio gerado pela precariedade de obras de saneamento. Congresso Nacional de Meio Ambiente de Poços de Caldas. Poços de Caldas. Anais... Poços de Caldas: GSC. ISSN on-line 2317-9686, v. 3, n. 1, 2011.

ANA - Agência Nacional de Águas. Panorama da qualidade das águas superficiais do Brasil. 2012. Disponível em: http://arquivos.ana.gov.br/imprensa/publicacoes/Panorama_Qualidade_Aguas_ Superficiais_BR_2012.pdf. Acesso em: 29 set. 2016. 
ANA - Agência Nacional de Águas. Relatório de conjuntura dos Recursos Hídricos no Brasil. 2013. Disponível em: http://arquivos.ana.gov.br/institucional/spr/conjuntura/webSite_ relatorioConjuntura/projeto/index.html. Acesso em: 29 set. 2016.

ARAÚJO, E.P. et al. Delimitação das bacias hidrográficas da Ilha do Maranhão a partir de dados SRTM. XIV Simpósio Brasileiro de Sensoriamento Remoto, 14, 2009. Anais..., Natal, Brasil, 2009, INPE. p. 4631.

BRASIL. Lei no 9.433, de 8 de janeiro de 1997. Institui a Política Nacional de Recursos Hídricos. 1997. Disponível em: http://www.planalto.gov.br/ccivil_03/leis/L9433.htm. Acesso em: 1 out. 2016.

BRASIL. Ministério da Saúde. Portaria de Consolidação n 5, de 28 de setembro de 2017. Disponível em: http://bvsms.saude.gov.br/bvs/saudelegis/gm/2017/prc0005_03_10_2017.html. Acesso em: 13 mar. 2018.

CÂMARA, G. et al. Integrating remote sensingand GIS by object-oriented data modelling. Comp. Graph., v. 20, n. 3, p. 395-403. INPE. Programa Spring, versão 5.2.3. São Paulo: INPE, 2013. Disponível em: http://www.dpi.inpe.br/spring/portugues/download.php. Acesso em: 28 out. 2016.

CAPAZ, R. S.; NOGUEIRA, L. A. H. Ciências ambientais para engenharia. Rio de Janeiro: Elsevier, 2014.

DERISIO, J. C. Introdução ao controle da poluição ambiental. 4. ed. São Paulo: Signus, 2012.

FERREIRA, M. J. Impactos ambientais recentes na área da bacia do rio Santo Antônio, Paço do Lumiar - Ma. 2003. 41f. Monografia (Graduação em Geografia) - Universidade Federal do Maranhão, São Luís, 2003.

FEITOSA, A. C. Parâmetros analíticos dos sedimentos da praia do Canto, Paço do Lumiar - MA. Reunião Especial da SBPC, 3, 1996, Florianópolis. Ecossistemas costeiros: do conhecimento à gestão. Anais..., Florianópolis: UFSC, v. 1, 1996.

IBGE CIDADES. 2010. Disponível em: http://cidades.ibge.gov.br/xtras/uf.php?lang=\&coduf=21\&sear ch=maranhao. Acesso em: 5 out. 2016.

IMESC - Instituto Maranhense de Estudos Socioeconômicos e Cartográficos. Situação Ambiental da Ilha do Maranhão. São Luís: IMESC, 2011.

INPE - Instituto Nacional de Pesquisas Espaciais. Catálogo de imagens de satélite. São Paulo: INPE, 2013. MACÊDO, L. A. A. Gestão de águas do Maranhão: um estudo retrospectivo. São Luís: UNICEUMA, 2005. 
MAFRA, R.L.P. A dinâmica climática de São Luís. São Luís: UFMA, 2004.

MOTA, S. Urbanização e meio ambiente. Rio de Janeiro: ABES, 1999. 356p.

MOTA, S. Preservação e conservação de recursos hídricos. 2. ed. Rio de Janeiro: ABES. 1995.

NARDINI, R. C. Determinação do conflito de uso e ocupação do solo em áreas de preservação permanente da microbacia do ribeirão Água-Fria, Bofete (SP), visando a conservação dos recursos hídricos. 2009. 61f. Dissertação (Mestrado em Agronomia/Irrigação e Drenagem) Faculdade de Ciências Agronômicas, Universidade Estadual Paulista - UNESP, Botucatu-SP, 2009.

NUGEO - Núcleo Geoambiental. 2013. Disponível em: http://www.nugeo.uema.br/. Acesso em: 2 jun. 2017.

OLIVEIRA, D.B. Hidrologia. São Paulo: Pearson Education do Brasil, 2016.

POLETO, C. Bacias hidrográficas e recursos hídricos. Rio de Janeiro: Interciência, 2014.

RICHTER, C. A.; AZEVEDO NETTO, J. M. Tratamento de água: tecnologia atualizada. São Paulo: E. Blücher, 1991.

ROCHA, J. S. M. Manual de manejo integrado de bacia hidrográfica. Universidade Federal de Santa Maria, 1991.

ROMÃO, A. C. B. C.; SOUZA, M. L. Análise do uso e ocupação do solo na bacia do ribeirão São Tomé, noroeste do Paraná - PR. RA'EGA 21, Curitiba, p. 337-364, 2011.

ROSA, A.F. Os Impactos da urbanização sobre o ciclo hidrológico no município de Patrocínio

- MG. 2017. Trabalho de Conclusão de Curso (Curso em Engenharia Ambiental) - Universidade Federal de Uberlândia, Minas Gerais, 2017.

SANTOS, S. R. Águas doces no Brasil: capitais ecológicas, usos e conservação. São Paulo: Escrituras, 2006.

SILVA, R.N.M. et al. Oferta e demanda de água na Itha de São Luís. Congresso Brasileiro de Engenharia Sanitária e Ambiental, v. 23, Campo Grande. Anais..., Campo Grande: ABES, 2005. 
1 Engenheiro Ambiental. E-mail: fabiohbm.eng.amb@gmail.com

2 Acadêmico em Engenharia Ambiental, Universidade Ceuma. E-mail: moisessantos120@gmail.com

3 Acadêmica em Engenharia Ambiental, Universidade Ceuma. E-mail: pollyanna.pedrosa@hotmail.com

4 Acadêmica em Engenharia Ambiental, Universidade Ceuma. E-mail: larissa.nogueiravieira@hotmail.com

5 Acadêmico em Engenharia Ambiental, Universidade Ceuma. E-mail: manoelneto96@hotmail.com

6 Acadêmica em Engenharia Ambiental, Universidade Ceuma. E-mail: thalissa1949@hotmail.com

7 Acadêmica em Engenharia Ambiental, Universidade Ceuma. E-mail:camilaeverton33@gmail.com

8 Mestrado em Sustentabilidade de Ecossistemas; Engenheira Ambiental; Professora, Universidade Ceuma.

E-mail: prof.nathaliapinheiro@gmail.com

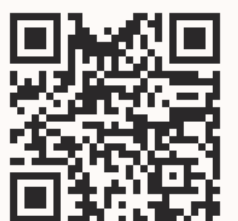

A autenticidade desse artigo pode ser conferida no site https://periodicos. set.edu.br

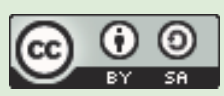

Este artigo é licenciado na modalidade acesso abertosob a Atribuição-Compartilhalgual CC BY-SA

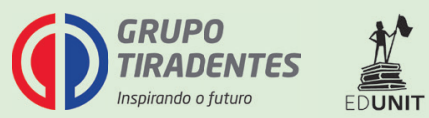

